\title{
Effects of ozone depletion and increased ultraviolet-B radiation on northern vegetation
}

\author{
Lars Olof Björn, Terry V. Callaghan, Carola Gehrke, \\ Dylan Gwynn-Jones, John A. Lee, Ulf Johanson, \\ Mats Sonesson \& Nicholas D. Buck
}

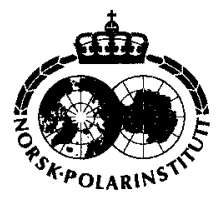

\begin{abstract}
The stratospheric ozone layer has been depleted at high and mid-latitudes as a consequence of man's pollution of the atmosphere, and this results in increasing ultraviolet- $B$ radiation at ground level. We investigate the effects of further radiation increases on plants and ecosystems by irradiating natural sub-Arctic and Arctic vegetation with artificial UV-B radiation in field experiments extending over several years. Our experimental sites are located at Abisko, in northern Sweden $\left(68^{\circ} \mathrm{N}\right)$, and Adventdalen, on the island of Spitsbergen $\left(78^{\circ} \mathrm{N}\right)$. Additional UV-B induced interspecific differences in plant response in terms of reduced (or, in one case. increased) growth, changed morphology and changed pigment content. In some cases effects seem to be accumulated from one year to another. Plant litter decomposition is retarded. We are also studying how UV-B enhancement may affect the interaction between species. In some experiments we combine UV-B enhancement with changes in other factors: carbon dioxide concentration, water availability, and temperature. In some cases the effect of radiation enhancement is modified, or even reversed, by such changes. Over a four year period we did not find any significant radiation induced change in species composition, but based on the effects on individual plant species, such changes can be expected to take place over a longer time.
\end{abstract}

L. O. Björn \& U. Johanson, Plant Physiology, Lund University, Box 117, SE-221 00 Lund, Sweden; T. V. Callaghan. Abisko Scientific Research Station, Box 62, SE-981 07 Abisko, Sweden; C. Gehrke, Plant Ecology, Ecology Building, Lund University, SE-223 62 Lund, Sweden; D. Gwynn-Jones, Institute of Biological Sciences, Edward Llwyd Building. University of Wales, Aberystwyth, Ceredigion SY23 3DA, Wales, UK; J. A. Lee \& N. D. Buck, The Sheffield Centre for Arctic Ecology, Dept. of Animal and Plant Sciences, University of Sheffield, 26 Taptonville Rd., Sheffield S1O SBR, UK; M. Sonesson, Plant Ecology, Ecology Building, Lund University, SE-223 62 Lund, Sweden.

\section{Introduction}

From 1979 until 1991 depletion of stratospheric ozone took place all over the world, except near the equator (WMO/UNEP 1998). During this period, the rate of ozone depletion was higher over northern Europe compared to some other regions at similar latitudes (see map, based on Nimbus 7 TOMS data compiled by J. Brandt and T. Knudsen, available on the internet at www. gfy.ku.dk/ tk/busstop/cases/trends/figcolor.htm). Though ozone over northern Europe decreased between 1988 and 1997, during the last couple of years no further depletion has taken place, so that the average depletion for the past 11 years is now
$0.23 \%$ per year (Fig. 1). Depletions of more than $15 \%$ have occurred during four winters in the past decade, while there has been little summer depletion. Because of stratospheric cooling associated with an increase in greenhouse gases and other possible interactions with atmospheric changes taking place, future developments are very uncertain. In any case, the ozone layer will not return to its original state for many decades yet, and the resultant increase in UV-B radiation (which is inferred but which, due to technical difficulties and lack of baseline data, has not yet been directly observed) will persist for a long time. There is therefore a strong reason to investigate the long-term effects of increased UV-B on aquatic 


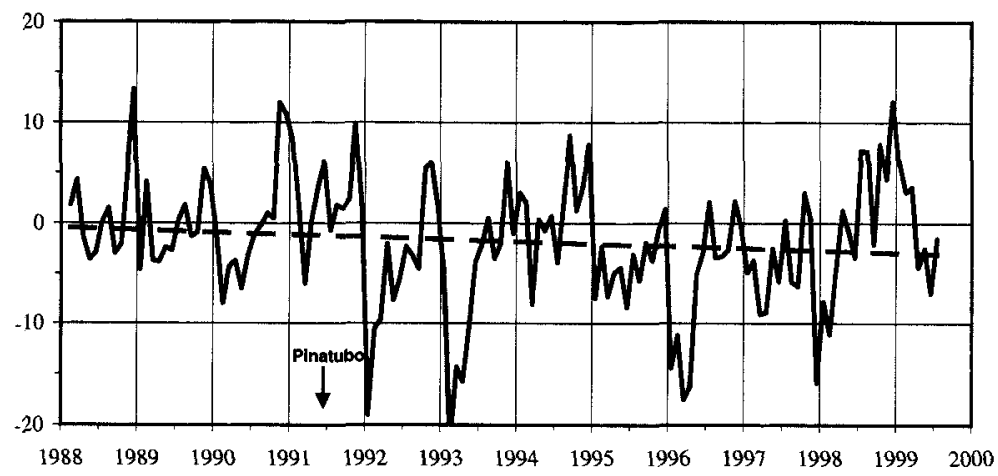

Fig. I. Deviation of column ozone (monthly averages of ground-based measurements) over Norrköping, Sweden, from the predepletion values. Pre-depletion values (zero line in the diagram) were measured over Uppsala (monthly averages 1951-1966). The long-term trend over the period February 1988 to July 1999 is indicated by the dashed line and corresponds to a decrease in the ozone layer by $2.3 \%$ per ten years. Because the last two years saw no ozone reduction, this contrasts dramatically with the average decrease rate of 8\% per ten years in the period 1988-1997. (Courtesy of Weine Josefsson, Swedish Hydrological and Meteorological Institute. The graph is available on the internet via the Institute's homepage and is planned to be continually updated.)

and terrestrial ecosystems. We have focused on the northern terrestrial ecosystems with an emphasis on plant responses.

\section{Photochemical UV-B damage to DNA and other biomolecules}

Many cell components can be altered by UV-B driven photochemical reactions, and in most cases such alteration results in impaired biological performance. DNA, a key component in all living cells, can be damaged in several ways by UV-B. The damage processes fall in two classes, i.e. (1) direct photochemical damage in which DNA absorbs a photon, and the excitation of the molecule results in a molecular change, and (2) photochemical reactions involving other molecules in which radicals or active oxygen species are generated and attack DNA. The two most common processes, belonging to the first class, are dimerization of the pyrimidine bases of DNA and formation of adducts, so-called (6-4) photoproducts. From their high frequency, it does not follow that these two kinds of lesion are the most important ones, since they are also the two most easily repaired. Their formation and repair is, in comparison with other kinds of DNA damage, relatively well explored.

UV-B can also result in damage to lipids, and therefore to membranes and membrane function. Indirectly this can also lead to DNA damage.
Photosynthesis by plants, algae and cyanobacteria involves two photosystems, of which photosystem II is particularly sensitive to UVB. Photosynthesis can also be inhibited by photochemical changes in other molecular components, such as the carbon dioxide binding enzyme, Rubisco. However, UV-B induced decreases in photosynthesis can also be due to gene regulation (Jordan et al. 1991; Mackerness, Butt et al. 1996); under ecologically relevant conditions this may be the most important mechanism. This downregulation proceeds via formation of active oxygen species (Mackerness, Surplus et al. 1998).

Many genes other than those involved in photosynthesis may be either up- or downregulated by UV-B. Radiation defence mechanisms in plants partly rely on such regulations, and gene regulations may, under the UV-B levels in daylight, be of greater ecological significance than the directly damaging actions of UV-B.

Some UV-B effects in plants may be mediated by a specific UV-B receptor; possibly the chromophore of this is a pterin (see Björn 1999 for a review). Another possibility is provitamin D (ergosterol or dehydrocholesterol). Many action spectra, peaking near $295 \mathrm{~nm}$ (Björn 1999) resemble the action spectrum (MacLaughlin et al. 1982) for provitamin $D_{3}$ to previtamin $D_{3}$ conversion in human skin. This conversion takes place in some plants under UV-B radiation (Prema \& Raghuramulu 1996; Wang \& Björn in prep.), and it is known that vitamin $D$ and some related 
Table 1. Effects of increased ultraviolet radiation (corresponding to $15 \%$ ozone depletion under cloudless skies) on plant growth parameters. Values are in all cases percent of control grown under natural radiation. For experimental details and statistics the original publications should be consulted. Experiments were in the field. except for Calamagrostis, in which case the values for a daily UV-B exposure of $5.3 \mathrm{~kJ} \mathrm{~m}^{-2}$ were compared to those obtained with $4.0 \mathrm{~kJ} \mathrm{~m}^{-2}$.

\begin{tabular}{lrc}
\hline & First year & Second year \\
\hline Leaf thickness (a) & & \\
Vaccinium myrtillus & 96 & 89 \\
V. uliginosum & 91 & 90 \\
V. vitis-idaea & 109 & 104 \\
Longitudinal stem growth (a, b) & & \\
Sphagnum fuscum & 80 & 71 \\
Vaccinium myrtillus & 82 & 89 \\
V. uliginosum & 91 & 90 \\
V. vitis-idaea & 105 & 73 \\
Empetrum hermaphroditum & 86 & 67 \\
Leaf dry mass (a, b) & & \\
Polytrichum commune & 92 & \\
Vaccinitum myrtillus & 86 & \\
V. uliginosum & 129 & \\
V. vitis-idaea & 116 & \\
Empetrum hermaphroditum & 107 & \\
\hline
\end{tabular}

Key to references in Tables 1-4: (a) Johanson et al. 1995; (b) Gehrke 1999; (c) Björn, Callaghan, Johnsen et al. 1997; (d) Gwynn-Jones \& Johanson 1996; (e) Gehrke 1998b; (f) Johanson 1997; (g) Björn, Callaghan, Gehrke et al. 1997.

compounds have developmental effects when applied to plants (Buchala \& Pythoud 1988).

\section{Physiological alterations in plants and effects on ecosystems caused by increased UV-B}

Increased UV-B causes inhibition of longitudinal growth (sometimes growth stimulation); changed

Table 2. Dry mass increment (values in parenthesis for increased $\mathrm{CO}_{2}$ ). Values were obtained as a difference between second year and first year weights. For key to references, see Table 1 .

Shoot dry mass increment Hylocomium splendens Vaccinium myrtillus (2nd year) Calluna vulgaris (2nd year) $100(101)(\mathrm{c})$ 81 (74) (c)

Root dry mass increment Vaccinium myrtillus (2nd year) Calluna vulgaris (2nd year)
Table 3. Effects of increased ultraviolet radiation (corresponding to $15 \%$ ozone depletion under cloudless skies) on extractable UV-B absorbing pigments (on a dry mass basis), except values for Vaccinium myrtillus and $V$. vitis-idaea, which are on an area basis. Pigments were extracted with acidified methanol or, in the case of Calamagrostis, with $96 \%$ ethanol, the UV absorption spectrum measured, and the pigments quantified as the area under the absorbance curve from 280 to $320 \mathrm{~nm}$. Values are percent of control grown under natural radiation. For key to references, see Table 1 .

\begin{tabular}{lrcr}
\hline & \multicolumn{3}{c}{ Year } \\
\cline { 2 - 4 } & 1st & 2nd & 3rd \\
\hline $\begin{array}{l}\text { Hylocomium splendens } \\
\text { Polytrichum commune }\end{array}$ & 107 & & $111(\mathrm{~b})$ \\
Sphagnum fuscum & 95 & & $79(\mathrm{~b})$ \\
Calamagrostis purpurea & & $96(\mathrm{e})$ & \\
C. lapponica & & & $80(\mathrm{~d})$ \\
Vaccinium myrtillus & & $109(\mathrm{~d})$ \\
V. vitis-idaea & & $154(\mathrm{f})$ \\
& & & $133(\mathrm{f})$ \\
& Previous & Current \\
& year & year \\
\hline Cassiope tetragona (myricetin) & 137 & $139(\mathrm{~g})$ \\
C. tetragona (quercetin) & 111 & $130(\mathrm{~g})$ \\
\hline
\end{tabular}

morphology - in many cases smaller and thicker leaves, but sometimes thinner leaves (Johanson et al. 1995; Johanson 1997; Table 1); changes in dry mass increase (Tables 1,2); increased tillering in grasses; changes in leaf angle; increased synthesis of many secondary compounds such as flavonoids (Table 3); effects on phenology (timing of flowering, fruit setting, etc.); chlorophyll content (Table 4) and other effects.

At the ecosystem level, changed morphology in plants can lead to changes in competition for light, nutrients and water. Changes in growth rate naturally have consequences for herbivores. To an even larger extent this holds for the changed synthesis of secondary compounds and other

Table 4. Effects of increased ultraviolet radiation (corresponding to $15 \%$ ozone depletion under cloudless skies) on total chlorophyll (on a dry mass basis). Values are percent of control grown under natural radiation. Chlorophyll was extracted either with $80 \%$ acetone or, in the case of Calamagrostis, with $96 \%$ ethanol, and determined spectrophotometrically. For key to references, see Table 1 .

$\begin{array}{ll}\text { Hylocomium splendens (third year) } & 95 \text { (b) } \\ \text { Polytrichum commune (third year) } & 88 \text { (b) } \\ \text { Sphagnum fuscum (second year) } & 90 \text { (e) } \\ \text { Calamagrostis purpurea } & 65 \text { (d) } \\ \text { C. lapponica } & 85 \text { (d) }\end{array}$


changes in chemical composition. Compounds such flavonoids can act either as attractants or deterrents, resulting in changes in herbivory and thus feedback effects to the vegetation. The changes in timing may result in asynchrony with pollinators and thus provide another feedback loop. In general, changes in ecological interactions may amplify and modify the physiological effects of UV-B in a way which cannot be predicted from results obtained in single plant experiments. General reviews on ecosystem effects are provided by Björn (1996) and Rozema et al. (1997).

\section{Interactions with other factors}

For accurate evaluation of experiments on UV-B effects on plants it is important to specify not only the UV-B treatment, but also other experimental factors, since global change involves not only changes in UV-B climate, but also changes in carbon dioxide concentration and temperature. It has been shown that interactions between carbon dioxide and UV-B are generally weak, i.e. the two factors act independently (e.g. Björn, Callaghan, Johnsen et al. 1997). We return to the temperature factor below.

One factor which interacts very strongly with UV-B is visible radiation. Strong visible light has a pronounced ameliorating effect on UV-B damage and UV-B inhibition of physiological processes in plants. For this reason, early indoor experiments gave an exaggerated impression of the negative effects of UV-B, since lighting in growth chambers inadequately simulated natural daylight. Realistic conclusions can be drawn only from field experiments, such as those described below.

The ameliorating effect of visible light is mediated by several mechanisms: (1) Two important DNA enzymes, so-called photolyases, are activated by light (see Björn 1996). (2) Other UV$B$ effects, including down regulation of photosynthetic enzymes (and thus inhibition of photosynthesis) are counteracted by photosynthesis itself (Adamse \& Britz 1992; Mackerness, Butt et al. 1996).

\section{Specific concerns for biota at high latitudes in the perspective of ozone depletion}

UV-B in daylight at high latitudes never reaches the high levels characteristic of tropical mid-day light, for two reasons: (1) the ozone layer is thicker at higher latitudes; and (2) the sun never comes close to zenith, and thus the path length through the atmosphere (including the ozone layer) is much longer than that corresponding to a vertical direction. Because of this lower UV-B load to the biosphere at higher latitudes, one would be inclined to think that increased UV-B would not be a danger there. But a number of facts raise doubts about this:

(1) Relative UV-B increases are largest at higher latitudes, due to greater ozone depletion there. This may be more important than the absolute increases, since plants and other organisms throughout evolution have adjusted their defense systems (UV-B screening pigments, DNA repair systems, etc.) to low levels.

(2) Photochemical damage to DNA and other substances takes place through photochemical, temperature independent processes, which proceed equally rapidly at low as at high temperature. In contrast, repair systems are enzymatic, and work slowly at low temperature.

(3) Plants in the Arctic are living at the limit of their distribution. They are exposed to cold, water, and nutrient stress. Increase of yet another stress may therefore be crucial.

Our experiments so far have, however, not provided evidence that, in a short-term perspective, Arctic vegetation is particularly sensitive to UV-B enhancement (Tables 1, 2; Björn, Callaghan, Johnsen et al. 1997). Because damage may accumulate over time, we wish to extend the investigations over a longer period. Arctic plants are, as individuals, very long-lived. They propagate mainly vegetatively, and because the frequency of sexual reproduction is low, they would potentially be able to accumulate damage over extended periods.

\section{Methods of field experimentation}

UV-B effects have been studied in two ways in the field: by excluding or modifying ambient UV-B radiation with filters, and by supplementing the ambient radiation with artificial radiation from ultraviolet-emitting fluorescent lamps. Most of our experiments are of the latter kind.

To perform such experiments in an accurate 
way, one has to consider the spectrum, the timing, the irradiance and the angular distribution of radiation. However, due to technical and economic restrictions, some compromise has to be accepted in all these respects. The aim was not to reproduce the spectrum of natural daylight, but the difference between the spectra for ozone depleted and normal conditions. This is achieved by filtering the radiation from the lamps through sheets of cellulose acetate, which removes the UV-C (wavelength $<280 \mathrm{~nm}$ ) component, which is not present in ground-level daylight.

As for the timing and the irradiance, in most experiments a reliable and cost effective method was used. The irradiance from the lamps was measured and compared to a computer model for what additional amount of daily radiation would be caused by a certain percentage of ozone depletion, and then clock operated switches were set in such a way that this amount of radiation was delivered to the vegetation. In the morning half of the lamps are switched on, somewhat later the other half, and after noon the lamps were switched off sequentially. In this way we obtained a temporal distribution of the radiation over the day which in a rough way resembled the additional radiation which would be caused by ozone depletion. The time each lamp was on thus varied with the time of the year, but was on the order of two hours. The computer model for daylight UV-B is reasonably accurate only for cloud-free conditions, and thus this way of simulating ozone depletion is far from ideal.

In one of our more recent experiments we have taken up a method first used by Caldwell's group in Utah (see Caldwell et al. 1983), and later by Teramura and his colleagues in Maryland (see Björn \& Teramura 1993). In this experiment the output of the lamps was continuously regulated to follow the variations of ambient UV-B. One sensor monitors the ambient UV-B and two other sensors monitor the ambient plus the artificial UV-B, and a feedback system keeps a preset ratio between the signals. This ratio corresponds to a certain amount of ozone depletion irrespective of solar angle, actual amount of ozone, clouds, etc.

As for the angular distribution of radiation, biologically active UV-B radiation, in contrast to visible light, is very diffuse even if the sun is not obscured by clouds, i.e. it comes from the whole sky, and it is therefore an advantage to use extended fluorescent lamps rather than point sources. We usually employ either groups of six parallel 40 watt lamps, or sets of four 4 watt lamps arranged in a square, in such a way that we get a uniform irradiance over the vegetation under investigation.

\section{Some results with different kinds of vegetation}

\section{Mosses on an ombotrophic mire}

Large areas in the Arctic are covered by bogs (ombotrophic mires), and the mosses on bogs constitute important sinks of atmospheric carbon dioxide, which they deposit as peat. A major Arctic peat-forming moss, Sphagnum fuscum, showed inhibited extension growth with additional UV-B estimated to correspond to an ozone depletion of $19 \%$ (taking clouds into account) at Abisko. However, there was no inhibition of increase in dry weight (Gehrke 1998a, b).

We have recently concluded a two factor experiment in Abisko in which we study both Sphagnum fuscum and another moss, Dicranum elongatum, and where we increase both UV-B and the temperature. Preliminary results indicate that the effects of a small temperature increase has a much larger (and positive) effect on growth of both species than any effect of UV-B enhancement.

\section{Other mosses}

Several other species of moss have also been studied by our group, both in Abisko and on Spitsbergen. In some cases additional UV-B inhibits growth, but, quite unexpectedly, it can also have the opposite effect. If the moss Hylocomium splendens is provided with sufficient extra water on the rather dry heath in Abisko where the experiments were carried out, UV-B stimulates growth over the control (which is watered in the same way) (Gehrke \& Björn in prep.). If no extra water is provided, UV-B inhibits growth.

Contrary to most plants studied by other groups, the mosses studied did not increase their content of UV-B absorbing pigments with increased radiation (Table 3).

\section{Dwarf shrubs}

We have studied UV-B effects on four species of 
ericaceous dwarf shrubs, i.e. the deciduous Vaccinium uliginosum and V. myrtillus, and the evergreen $V$. vitis-idaea and Empetrum hermaphroditum. Differences among species were found both with respect to leaf growth and morphology, and stem growth (Johanson et al. 1995; Johanson 1997). The most interesting finding is that stem growth (which was inhibited in all species) was more inhibited in the second year of irradiation (as compared to the first year) in the evergreen species, but that this effect was not seen in deciduous species, and the effect did not continue over the following years.

In all ericaceous dwarf shrubs studied, the content of UV-B absorbing substances increased with increased radiation.

\section{Effects on litter decomposition and decomposing fungi}

The decomposition of plant litter was slowed down by additional UV-B, in two different ways (Gehrke, Johanson, Callaghan et al. 1995). Litter from plants which had received additional UV-B had a changed chemical composition, and was therefore more resistant to decomposition ("indirect effect"). Additional UV-B slowed down decomposition ("direct effect") via an inhibiting effect on the life processes of some of the decomposers (but not all the fungal species were equally sensitive). Effects on litter breakdown may in the long term affect plant nutrient availability.

\section{Other organisms}

We also have a number of other plants and other organisms under study. As an example of how ecological interactions can be modified by additional UV-B, radiation (corresponding to an ozone depletion of around 20\%) made caterpillars of the autumn moth, Epirrita autumnata, eat three times the usual amount of birch leaves (Buck 1999).

\section{Conclusions and outlook}

Direct impacts of realistic UV-B enhancement on sub-Arctic and Arctic terrestrial vegetation are not dramatic in a short time perspective. Indirect effects, via interactions of plants with other organisms and with the abiotic environment are probably more important. These indirect effects may take many years to be manifest as ecological dysfunction in Arctic ecosystems, dominated as they are by long-lived perennial plants, and are thus potentially very important.

Acknowledgements. - Most of the field work reported on here is part of the UVECOS project, sponsored by the Commission of European Communities (Contract No. EV5V-CT91-0032).

\section{References}

Adamse, P. \& Britz, S. J. 1992: Amelioration of UV-B damage under high irradiance. I: role of photosynthesis. Photochem. Photobiol. 56, 645-650.

Björn, L. O. 1996: Effects of ozone depletion and increased UVB on terrestrial ecosystems. Int. J. Environ. Stud. 51, 217-243.

Björn, L. O. 1999: UV-B effects: receptors and targets. In G. S. Singhal et al. (eds): Concepts of photobiology. Pp. 821-832. New Delhi: Narosa Publishing House.

Björn, L. O., Callaghan, T., Gehrke, C., Gunnarsson, T., Holmgren, B., Johanson, U., Snogerup, S., Sonesson, M., Sterner, O. \& Yu, S.-G. 1997: Effects on subarctic vegetation of enhanced UV-B radiation. In P. Lumsden (ed.): Plant and UV-B: responses to environmental change. Pp. 233-246. Cambridge: Cambridge University Press.

Björn, L. O., Callaghan, T. V., Johnsen, I., Lee, J. A., Manetas, Y., Paul, N. D., Sonesson, M., Wellburn, A., Coop, D., HeideJørgensen, H. S., Gehrke, C., Gwynn-Jones, D., Johanson, U., Kyparissis, A., Levizou, E., Nikolopoulos, D., Petropoulou, Y. \& Stephanou, M. 1997: The effects of UV-B radiation on European heathland species. Plant Ecol. 128, 252-264.

Björn, L. O. \& Teramura, A. H. 1993. Simulation of daylight ultraviolet radiation and effects of ozone depletion. In A. R. Young et al. (eds.): Environmental photobiology, Pp. 41-71. London: Plenum Publishing.

Buchala, A. J. \& Pythoud, F. 1988: Vitamin D and related compounds as plant growth substance. Physiol. Plant. 74, 391-396.

Buck, N. D. 1999: The direct and indirect effects of enhanced $U V-B$ on plant-insect herbivore interactions. $\mathrm{PhD}$ thesis, Dept. of Animal and Plant Sciences, University of Sheffield, UK. $206 \mathrm{pp}$.

Caldwell, M. M., Gold, W. G., Harris, G. \& Ashurst, C. W. 1983. A modulated lamp system for solar UV-B $(280-320 \mathrm{~nm})$ supplementation studies in the field. Photochem. Photobiol. 37, 479-485.

Gehrke, C. 1998a: Effects of enhanced ultraviolet-B radiation on subarctic ecosystems. Dissertation, Lund University, Sweden. ISBN 91-7105-101-5.

Gehrke, C. 1998b: Effects of enhanced UV-B radiation on production related properties of a Sphagnum fuscum dominated subarctic bog. Funct. Ecol. 12, 940-947.

Gehrke, C. 1999: Impacts of enhanced ultraviolet-B radiation on two mosses with contrasting morphology and growth patterns in a subarctic heath ecosystem. Ecology 80(6), 1844-1851. 
Gehrke, C., Johanson, U., Callaghan, T. V., Chadwick, D. \& Robinson, C. 1995: The impact of enhanced ultraviolet-B radiation on litter quality and decomposition processes in Vaccinium leaves from the subarctic. Oikos 72, 213-222.

Gwynn-Jones, D. \& Johanson, U. 1996: Growth and pigment production in two subarctic grass species under four different UV-B irradiation levels. Physiol. Plant. 97, 701-707.

Johanson, U. 1997: Future stratospheric ozone depletion will affect a subarctic dwarf shrub ecosystem. Dissertation, Lund University, Sweden. ISBN 91-628-2404-X.

Johanson, U., Gehrke, C., Björn. L. O. \& Callaghan, T. V. 1995: The effects of enhanced UV-B radiation on the growth of dwarf shrubs in a subarctic heathland. Funct. Ecol. 9 . 713-719.

Jordan, B. R., Chow, W. S., Strid, Å. \& Anderson, J. M. 1991: Reduction in $C a b$ and psA RNA transcripts in response to supplementary UV-B radiation. FEBS Lett. 284, 5-8.

Mackerness, S. A. H., Butt, P. J., Jordan, B. R. \& Thomas, B. 1996: Amelioration of ultraviolet-B-induced down-regulation of mRNA levels for chloroplast proteins by high irradiance is mediated by photosynthesis. J. Plant. Physiol. 148, 100-106.

Mackerness, S. A. H., Surplus, S. L., Jordan, B. R. \& Thomas, B. 1998: Effects of supplementary ultraviolet-B radiation on photosynthetic transcripts at different stages of leaf development and light levels in pea (Pisum sativum L.): role of active oxygen species and antioxidant enzymes. Photochem. Photobiol. 68, 88-96.

MacLaughlin, J. A., Anderson, R. R. \& Holick, M. F. 1982: Spectral character of sun light modulates photosynthesis of pre vitamin $\mathrm{D}_{3}$ and its photoisomers in human skin. Science 216, 1001-1003.

Prema, T.P. \& Raghuramulu, N. 1996: Vitamin $D_{3}$ and its metabolites in the tomato plant. Phytochemistry 42, 617-620.

Rozema, J., van de Staaij, J., Caldwell, M. M. \& Björn, L. O. 1997: UV-B as an environmental factor in plant life: stress and regulation. Trends Ecol. Evol. 12, 22-28.

WMO/UNEP 1998: Scientific assessment of ozone depletion 1998. Nairobi: World Meteorological Organization and United Nations Environment Programme. 